\title{
Diaphragmatic Hernia with very late presentation after Penetrating Trauma: A case reports.
}

\author{
Ilir Skenduli ${ }^{1 *}$, Fatmir Caushi ${ }^{1}$, Arjan Mezini ${ }^{2}$, Laert Gjati ${ }^{2}$
}

Received: 01 December 2021 / Accepted: 19 December 2021 / Published online: 20 January 2022

This article is published with open access at https://journal.astes.org.al

(C) The author(s) 2022. \& Copyright (C) 2022, the Albanian Society for Trauma and Emergency Surgery

(c) The Albanian Journal of Trauma and Emergency Surgery is an Open Access Journal. All articles are distributed under the terms of the Creative Commons Attribution Non-Commercial License: http://creativecommons.org/licenses/by-nc/4.0/) which permits unrestricted non-commercial use, distribution, and reproduction in any medium provided the original work is properly cited.

\begin{abstract}
Blunt traumatic rupture of the diaphragm is a serious injury that is often difficult to diagnose. [1]

Diaphragmatic injuries were described first by Sennertus in 1541. Riolfi performed the first successful repair in 1886.

In 1951, Carter published the first case series, was this injury well understood and delineated. [2]

Approximately $0.8 \%-1.6 \%$ of patients with blunt trauma show a rupture in the diaphragm. (3) Blunt trauma accounts for $75 \%$ of ruptures and penetrating trauma accounts for the rest. Approximately $69 \%$ of hernias are left-sided, $24 \%$ are right-sided, and $15 \%$ are bilateral. [3]

The occult diaphragmatic injury was uncovered in a patient who has blunt chest trauma, after penetrating trauma. Diaphragmatic injury can be a difficult diagnosis in the setting of trauma and a significant number of injuries are missed on the initial presentation.

We will be reporting a 56-year-old female who was admitted to our hospital with a history of cough, pain in the left chest as well as breathlessness of five days duration. She had a history of blunt trauma caused by an accidental gunshot in $1987 \ldots$
\end{abstract}

Keywords: blunt Trauma, diaphragmatic injury, chest trauma

\section{Background}

Traumatic injury to diaphragm is an uncommon condition associated with severe blunt trauma which is usually missed in the early presentation to emergency. [1] The initial diagnosis of a blunt traumatic injury to the diaphragm is generally difficult because the early clinical and radiological findings are not clear. In acute circumstances, it is usually found on the table during exploratory laparotomy, although even then it may be missed. Nearly half of the patients remain asymptomatic and present with complications of the diseases several years after the onset of initial trauma.

Original article, no submission or publication in advance or in parallel

\footnotetext{
* Corresponding author:

Ilir Skenduli MD

$\bowtie \quad$ skenduli2004@yahoo.com

1 Department of Thoracic Surgery, University Hospital "Shefqet Ndroqi", Tirana, ALBANIA

2 Department of Pneumology, University Hospital "Shefqet Ndroqi", Tirana, ALBANIA
}

In developing countries, where initial care of severely injured patients and diagnostic facilities are less than optimal, blunt traumatic diaphragmatic rupture may go undiagnosed. High index of clinical suspicion is required because of the missed diagnosis and potential for delayed presentation. We report a case of delayed presentation of post traumatic diaphragmatic hernia and reviewed the literature to highlight challenges in diagnosis and management of such cases. [3]

\section{Case Report}

A 56-year-old female was admitted in our hospital with a history of cough, pain in left chest as well as breathlessness of five days duration.

She had a history of a blunt trauma caused by accidental gunshot in 1987. She was transferred to the regional hospital where the patient underwent the removal of the bullet from the left axilla. The patient was then treated conservatively and no diaphragmatic hernia was detected. The chest X-ray showed a moderate air-fluid level in the left thoracic cavity. CT scan revealed a posterior defect on the left diaphragm with herniation of great omentum in thoracic cavity, as shown in Fig.1. 


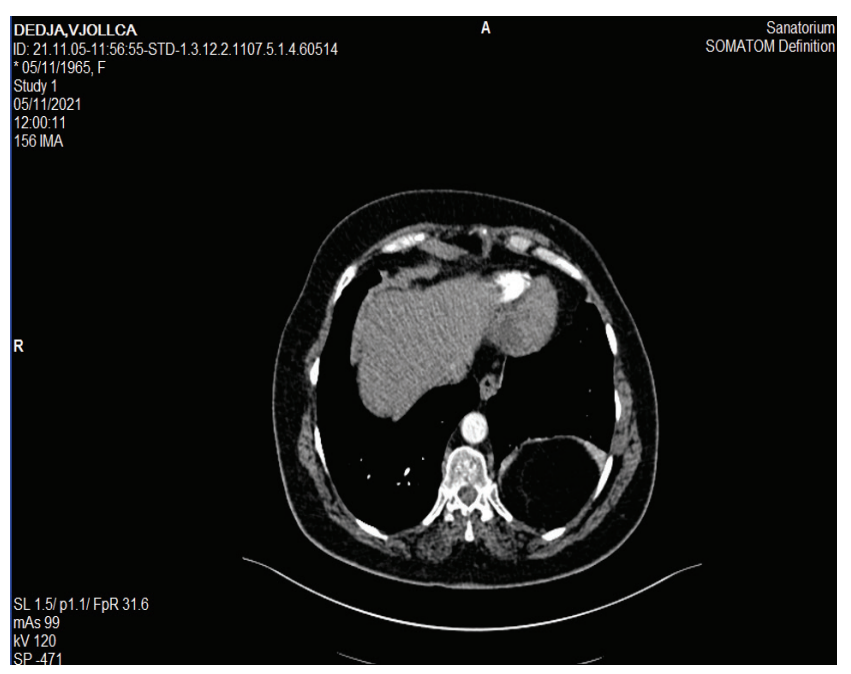

Figure 1 The great omentum in the thoracic cavity (sagital view)

The patient underwent left posterolateral thoracotomy and reduction of herniated great omentum into abdominal cavity first, and then the defect of diaphragm was repaired with single layer non absorbable suture. Her postoperative recovery was uneventful and she left the hospital after five postoperative days.

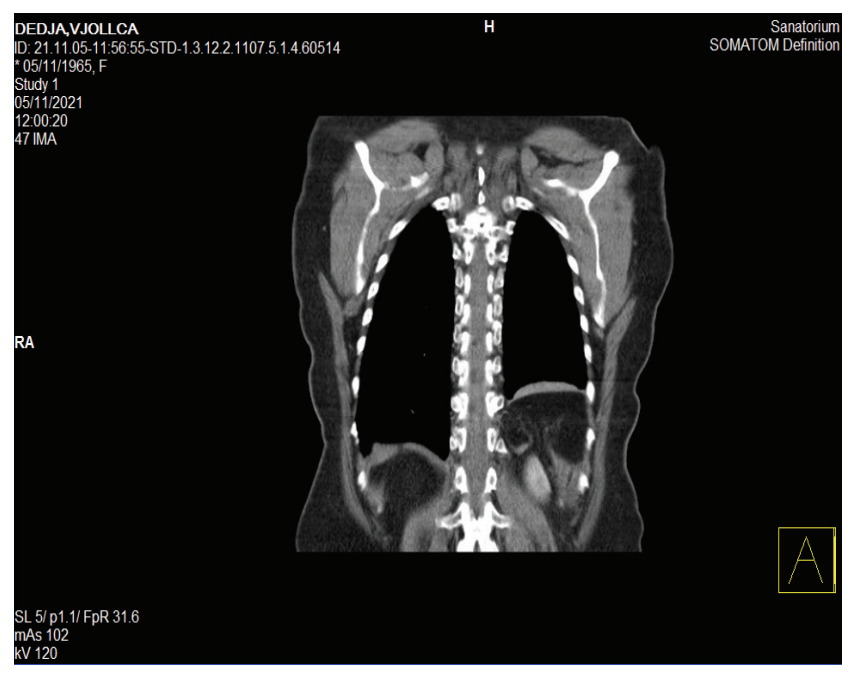

Figure 2. Diaphragmatic hernia (coronal view)

\section{Discussion}

The traumatic DH was apparently reported by Sennertus in 1541. Ambroise Pare described the first case of DH at autopsy in 1579. Antemortem diagnosis of traumatic DH was first made by Bowditch in 1853 and the first successful repair was done by Riolfi in 1886 . [1]

The reported incidence of diaphragmatic rupture is between 0.9 and 1.8 percent of the patients admitted to the hospital with blunt trauma. [2]

The incidence rises up to $15 \%$ among patients with penetrating trauma Male to female ratio of traumatic DH is $4: 1$ and most of them present in the third decade of life. Commonest site of rupture is the posterolateral surface along the embryonic fusion line because it is the weakest part of the diaphragm. [3]

Left sided rupture occurs in $70 \%-80 \%$ cases, right sided rupture in $15 \%-24 \%$ cases, and bilateral in $5 \%-8 \%$ cases. The greater prevalence of left sided rupture is due to buffer effect of the liver, embryonic weakness of the liver, embryonic weakness of left hemidiaphragm, and underdiagnosis of right diaphragmatic rupture. [4] Pathognomonic signs include visualization of herniated stomach or bowel in the chest and extension of intragastric tube above the level of diaphragm CT scan of the thorax is a useful aid in the diagnosis in urgent or uncertain cases. [5]

The important signs are sharp discontinuation of the diaphragm, intrathoracic visceral herniation, lack of visualization of the diaphragm (absent diaphragm sign), and constriction of bowel or stomach at the site of herniation (collar sign). [6, 7, 8]

Thoracotomy (if required, extended into a thoracoabdominal incision) is advised in the patients with delayed presentation since the adhesions within the chest can be freed easily and reduction and repair of hernia will be easily accomplished.

\section{Conclusion}

Traumatic DH is often missed if it occurs after seemingly innocuous injury or has a delayed presentation. Diagnosis should be reached as early as possible to reduce mortality.

To make radiological diagnosis, radiologists should be familiar with a variety of imaging presentations of injury and maintain a high index of suspicion.

In a clinically suspected case, if the chest X-ray is noncontributory, further imaging should be advised.

Open surgery or endoscopic surgery should be performed immediately to diagnose and treat the injury.

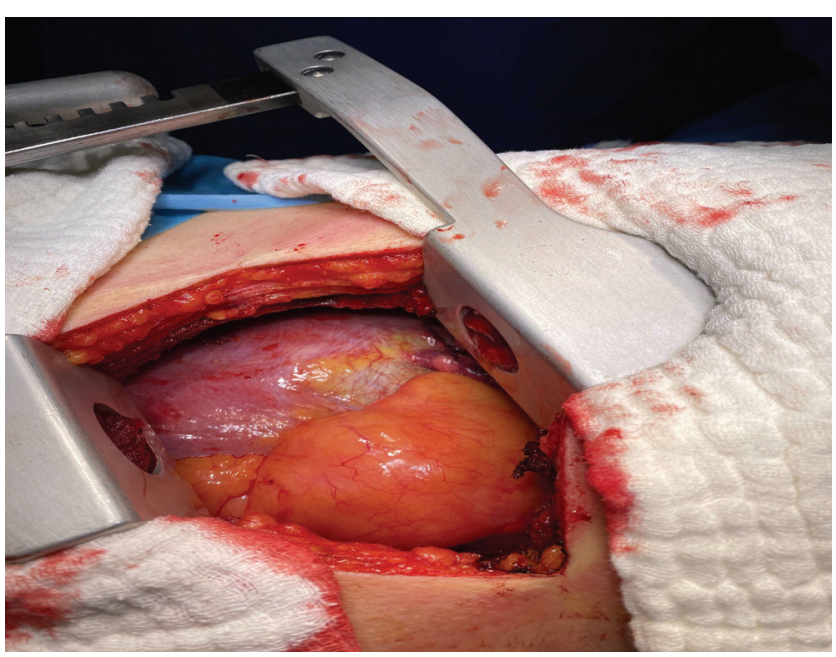




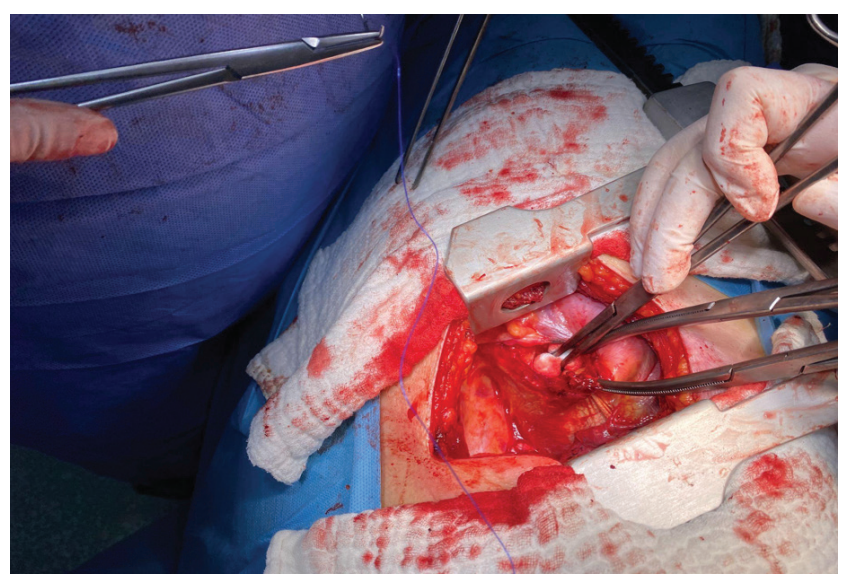

Figure 4 Hernia defect 3-4 cm in size in the left diaphragm

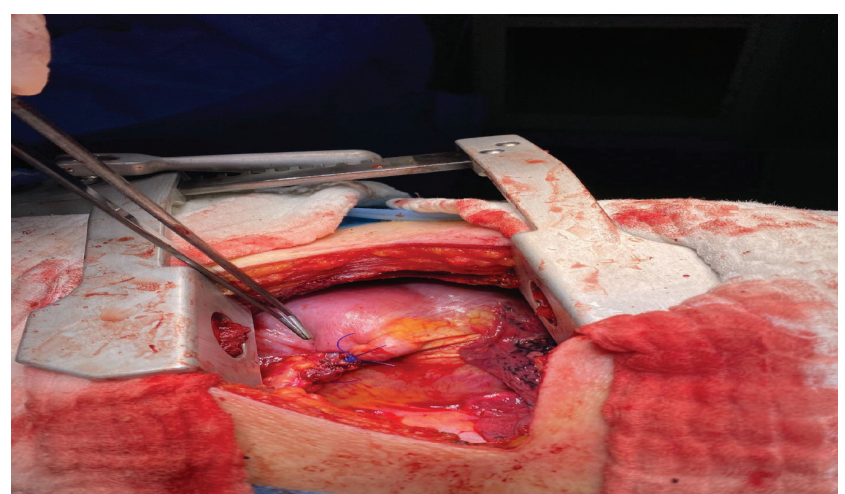

Figure 5. Surgical repair with single layer non absorbable suture

Competing interests - The authors declare that they have no known competing financial interests or personal relationships that could have appeared to influence the work reported in this paper.

The study has not been presented elsewhere!

Author Contributions. IS. conceived and designed the analysis, collected the data, treatment of all the patients in the article, observed the patients, contributed the data and analyses tools, performed the analysis and Interpretations, literature search, wrote the paper, other contributions (take the pictures), supervisor of the project, critical reviewer. FC, $\mathrm{AM}, \mathrm{LGj}$ conceived and designed the analysis, collected the data, treatment of all the patients in the article, wrote the paper, other contributions (take the pictures), critical reviewer, literature search.
Ethics approval and consent to participate - all the patients/their parents have signed informed consent.

Consent for photography- all the patients/their parents have signed informed consent

Consent for publication - all the patients/their parents have signed informed consent

Clinical trial registration information provided - not applicable

We confirm that the manuscript, including related data, figures and tables has not been previously published and that the manuscript is not under consideration elsewhere.

\section{References}

1. Galimberti A, Casagrande A, Compagnoni BM, Sansonetti G, et al. Late post-traumatic diaphragmatic hernia: Unusual cause of colonic occlusion. Chir Ital (Abstract) 2001; 53:551-554 [PubMed] [Google Scholar]

2. Welsford M. Diaphragmatic Injuries. Med J 2001; 2:726 [Google Scholar]

3. Feliciano DV, Cruse PA, Mattox KL, Bitondo CG, Burch JM, Noon GP, et al. Delayed diagnosis of injuries to the diaphragm after penetrating wounds. J Trauma 1988; 28:1135-44 [PubMed] [Google Scholar]

4. Cristofaro, M. G., Lazzaro, F., Cafaro, D., Natale, R., Mauro, P., Savino, N., \& Musella, S. (2000). Post-traumatic diaphragmatic hernia with late diagnosis. Report of a clinical case. Annali italiani di chirurgia, 71(5), 595-598.

5. Ganie, F. A., Lone, G. N., Chowdhary, M., \& Lone, H. (2013). The characteristics and surgical approach in post-traumatic diaphragmatic hernia: a single center experience. Bulletin of Emergency \& Trauma, 1(3), 108.

6. Hajong, R., \& Baruah, A. (2012). Post-traumatic diaphragmatic hernia. Indian Journal of Surgery, 74(4), 334-335.

7. Hood, R. M. (1971). Traumatic diaphragmatic hernia. The Annals of thoracic surgery, 12(3), 311-324.

8. Dogjani A, Kolani H, Haxhirexha K, Gjata A, Selmani E, et al. (2020) Considerations about Traumatic Diaphragmatic Rupture, Case Series and Review of Literature. J Surg 5: 1315. DOI: $10.29011 / 2575-9760.001315$ 